\title{
BETWEEN HERE-AND-NOW AND HEREAFTER: MINDFULNESS SEBAGAI PENGAWAL ORIENTASI TERHADAP KEHIDUPAN DAN KETAKUTAN TERHADAP KEMATIAN
}

\author{
Cleoputri Yusainy, Ilhamuddin, Amir Hasan Ramli, Bima Pusaka Semedi, Calvin \\ Octavianus Anggono, Maria Ulfatul Mahmudah, Alfi Rizki Ramadhan
}

\author{
Departemen Psikologi, Fakultas Ilmu Sosial dan Ilmu Politik, Universitas Brawijaya \\ Jl. Veteran Malang 65145 \\ cleo.yusainy@ub.ac.id
}

\begin{abstract}
Death as an existential problem has given birth to two large spectra: fear of death or accepting it as an inevitable truth. This study aimed to examine the extent to which an individual's fear of death could be predicted by anticipation of the future (life orientation) and tendency of being here-and-now (trait mindfulness). Self-reported questionnaires of life orientation in optimism-pessimism continuum, trait mindfulness, and fear of death were presented through cloud-based online survey $(N=218$ students, $73.585 \%$ females, average age 20.840 years, $S D$ $=1.777$ ). Hierarchical regressions analyses revealed that (i) optimistic orientation predicted a higher level of fear of death, (ii) trait mindfulness accounted for significant variance in fear of death after accounting for life orientation, and (iii) trait mindfulness did not moderate the link between life orientation and fear of death. The role of trait mindfulness was consistent in predicting lower levels of fear of death and dying of self as well as death of others, but not of dying of others. Additionally, women reported a higher level of fear of death, independent of life orientation and trait mindfulness. These individual differences should be taken into consideration when designing strategies to manage fear of death.
\end{abstract}

Keywords: fear of death; life orientation; trait mindfulness; optimism; pessimism

\begin{abstract}
Abstrak
Sebagai suatu problem, kematian melahirkan dua spektra besar: Takut mati atau menerima kematian sebagai ujung kehidupan yang harus dijalani. Penelitian ini bertujuan memetakan sejauh mana ketakutan individu terhadap kematian dapat diprediksi oleh antisipasinya terhadap masa depan (orientasi terhadap kehidupan) dan kecenderungannya untuk sadar penuh-hadir utuh (trait mindfulness). Kuesioner self-report orientasi terhadap kehidupan dalam kontinum optimisme-pesimisme, trait mindfulness, dan ketakutan terhadap kematian disajikan melalui survei online berbasis cloud $(N=218$ mahasiswa; $73,585 \%$ perempuan; rerata usia 20,840 tahun, $S D=$ 1,777). Analisis regresi hirarki menunjukkan (i) optimisme memprediksi ketakutan yang lebih tinggi terhadap kematian, (ii) setelah memperhitungkan peran orientasi terhadap kehidupan, trait mindfulness memprediksi ketakutan yang lebih rendah terhadap kematian, dan (iii) trait mindfulness tidak berperan sebagai moderator hubungan antara orientasi terhadap kehidupan dan ketakutan terhadap kematian. Peran trait mindfulness konsisten dalam memprediksi dimensi-dimensi terkait kematian, kecuali ketakutan terhadap proses sekarat orang lain. Terlepas dari orientasi terhadap kehidupan dan trait mindfulness, perempuan melaporkan ketakutan yang lebih tinggi terhadap kematian. Strategi mengelola ketakutan terhadap kematian perlu dilakukan dengan memperhitungkan perbedaan individual.
\end{abstract}

Kata kunci: ketakutan terhadap kematian; orientasi terhadap kehidupan; trait mindfulness; optimisme; pesimisme

\section{PENDAHULUAN}

Secara filosofis, kehidupan seorang manusia tidak dimulai sejak kelahiran, namun ketika manusia terpikir akan kematian. Tema sentral kemanusiaan, tidak bisa dilepaskan oleh satu episode dalam hidup, yaitu kematian.
Sebagai peristiwa yang mengaborsi perjalanan hidup, kontra kehidupan, kematian dianggap sebagai akhir dari segala hal yang telah dipunyai sepanjang hidup.

Teori klasik Terror Management Theory (TMT) dari Greenberg, Pyszczynski, dan 
Solomon (1986) dan Solomon, Greenberg, dan Pyszczynski (1991, 2015) bersumber dari karya seminal Becker (1973) yang menyatakan bahwa kesadaran manusia akan kematian serta kebutuhannya akan pencarian makna hidup merupakan motivasi fundamental yang mengarahkan segala bentuk proses mental dan perilaku. Menurut teori TMT, berbagai pemicu yang mengingatkan manusia akan kematian bisa melahirkan ketakutan terhadap kematian (fear of death)-dikenal juga dengan istilah kecemasan terhadap kematian (death anxiety) yang berpotensi untuk menciptakan suatu bentuk teror eksistensial. Pada tataran praktis, ketakutan terhadap kematian membawa dampak negatif karena berkaitan erat dengan gangguan mental-emosional seperti neurotisme, gangguan kecemasan, depresi, dan perilaku beresiko (Arndt, Routledge, Cox, \& Goldenberg, 2005; Iverach, Menzies, \& Menzies, 2014), serta kecenderungan untuk mendukung solusi kekerasan atas konflik (Hirschberger dkk., 2016). Dengan demikian perlu diupayakan agar tingkat ketakutan terhadap kematian dapat dikelola, sehingga kehidupan dapat dijalani dengan lebih bermakna.

Dual process model yang didasarkan pada teori TMT berargumen bahwa ada dua cara utama yang ditempuh untuk menghadapi pikiran-pikiran yang terkait dengan kematian, yaitu cara proksimal dan cara distal (Pyszczynski, Solomon, \& Greenberg, 2015). Cara proksimal adalah usaha sadar seseorang untuk menjauhkan pikiran mengenai kematian secara aktif ("Saya belum akan mati," atau, "Kematian masih jauh dari saya."). Cara proksimal memungkinkan manusia untuk menyingkirkan pemikiran mengenai kematian tanpa menegasi fakta bahwa kematian adalah suatu kepastian. Di sisi lain, cara distal berkembang sebagai upaya untuk membentuk ide-ide yang membuat kematian menjadi tetap tertutupi. Misalnya dengan memperkuat pandangan akan dunia (worldview) yang ditanamkan oleh budaya dan masyarakat, identitas kelompok, dan relasi interpersonal yang bermakna. Dengan cara-cara distal, seseorang meyakinkan diri bahwa ia adalah seseorang yang berharga dan bahwa hidupnya memiliki makna. Melalui cara-cara distal, pemikiran tentang kematian berada di luar kesadaran, namun secara implisit tetap memengaruhi kehidupan individu.

Ketakutan terhadap kehidupan setelah kematian ("hereafter"), seperti halnya pencarian terhadap makna hidup, melibatkan antisipasi yang dimiliki seseorang terhadap masa depan. Penelitian terdahulu belum menghasilkan simpulan yang konklusif mengenai manfaat dari pencarian makna hidup (Steger, Kashdan, Sullivan, \& Lorentz, 2008), akan tetapi survei Lyke (2013) dengan sampel komunitas menemukan bahwa semakin tinggi pencarian makna hidup, semakin tinggi pula ketakutan terhadap kematian. Terlepas dari makna hidupnya, selalu terbuka kemungkinan bahwa manusia akan berhasil atau gagal di masa depan. Ekspektansi individu terhadap masa depan bisa mengambil bentuk orientasi terhadap kehidupan yang dipetakan pada kontinum optimisme dan pesimisme (Scheir \& Carver, 1985; Scheier, Carver, \& Bridges, 1994). Seseorang mungkin menampilkan orientasi optimis pada area kehidupan tertentu (misalnya, dalam karir) dan orientasi pesimis pada area lain (dalam relasi personal). Kecenderungan yang relatif konsisten pada salah satu orientasi mungkin pula terjadi pada sebagian besar area kehidupan. Dalam kehidupan sehari-hari, orang yang cenderung mengharapkan terjadinya hal-hal baik disebut individu yang optimis, orang yang cenderung mengharapkan terjadinya hal-hal buruk disebut individu yang pesimis.

Literatur Psikologi mencatat bahwa perbedaan yang tampaknya sederhana dalam hal orientasi terhadap kehidupan ternyata memiliki pengaruh substansial. Individu yang optimis dan pesimis berbeda dalam cara mengatasi masalah, kemampuan untuk bangkit dari kegagalan, serta sumber daya sosial dan ekonomi (lihat tinjauan Carver, Scheier, \& Segerstrom, 2010). Secara 
biologis, studi Hecht (2013) menunjukkan bahwa meskipun pengalaman manusia selalu dimediasi oleh hemisfer kiri dan kanan, kecenderungan optimis lebih memiliki asosiasi dengan proses neurofisiologis pada hemisfer kanan (motor dexterity), sedangkan kecenderungan pesimis memiliki asosiasi dengan aktivitas pada hemisfer kiri (kewaspadaan terhadap bahaya).

Orang-orang yang optimis seharusnya memiliki ekspektansi yang lebih baik mengenai kematian, karena pada saat yang bersamaan ia juga mengantisipasi durasi hidup yang lebih lama. Mereka mungkin pula berpikir bahwa setelah kematian mereka nantinya, makna hidup mereka akan tetap tertinggal. Masih terbatas penelitian yang mengeksplorasi asosiasi antara optimisme dan ketakutan terhadap kematian, namun sebagian telah menemukan asosiasi yang negatif pada partisipan mahasiswa (Brown, 2011) dan penderita kanker (Sigal, Ouimet, Margolese, Panarello, Stibernik, \& Bescec, 2007). Meskipun demikian, optimisme berlebihan dapat mendorong bias atensi terhadap stimulus positif, sehingga individu menjadi abai terhadap risiko dari berbagai tindakan yang ia ambil (Sharot, 2011). Fokus pertama penelitian ini adalah untuk menguji sejauh mana ketakutan terhadap kematian dapat diprediksi oleh orientasi terhadap kehidupan dalam kontinum optimismepesimisme.

Idealnya, agar manusia dapat mempertahankan hidupnya sekaligus mencapai kesejahteraan hidup, diperlukan keseimbangan antara antisipasi terhadap masa depan dan kesadaran atas realita hidup yang sedang ia jalani saat ini. Mindfulness, dipahami pula dengan istilah "sadar penuh-hadir utuh", dan "here-and-now" (Silarus, 2015) sebagai trait merujuk pada kecenderungan alamiah untuk memberikan atensi dan menyadari secara penuh pengalaman hidup sehari-hari (Brown \& Ryan, 2003). Rangkaian eksperimen Niemiec dkk. (2010) menunjukkan bahwa meskipun individu yang mindful lebih peka dengan isu kematian namun sikap yang diambil lebih tidak defensif secara proksimal maupun distal. Trait mindfulness memiliki korelasi positif dengan optimisme (lihat Brown \& Ryan, 2003), dan kontribusi trait ini sebagai penawar berbagai situasi yang menimbulkan stres serta dalam meningkatkan kesejahteraan individu bahkan berada di atas peran optimisme (Weinstein, Brown, \& Ryan, 2009). Sejauh mana peran trait mindfulness dalam memprediksi ketakutan terhadap kematian setelah memperhitungkan peran orientasi terhadap kehidupan adalah fokus kedua penelitian ini.

Jika orientasi terhadap kehidupan dan trait mindfulness berfungsi secara independen dalam memprediksi ketakutan terhadap kematian maka trait mindfulness memiliki potensi untuk berperan sebagai moderator hubungan antara orientasi terhadap kehidupan dan ketakutan terhadap kematian. Melalui mindfulness, pengalaman individu dapat lebih terkelola karena ia tidak terlalu erat menggenggam (over-engagement) halhal yang ia sukai sekaligus tidak terlalu keras menendang (under-engagement) hal-hal yang tidak ia sukai (Hayes \& Feldman, 2004). Individu yang mindful lebih sedikit menampilkan berbagai perilaku yang bersifat menyakiti diri sendiri maupun orang lain (Yusainy \& Lawrence, 2014). Perilaku menyakiti diri sendiri dan orang lain dapat dipicu oleh ketidakcakapan individu dalam mengelola pengalamannya secara adaptif. Kondisi ini diperkirakan terjadi pula dalam konteks pengalaman yang bersumber pada kematian. Kontribusi trait mindfulness dalam memoderasi asosiasi antara orientasi terhadap kehidupan dan ketakutan terhadap kematian adalah fokus terakhir penelitian ini.

\section{METODE}

Penelitian ini merupakan studi korelasional yang dilakukan melalui survei online berbasis cloud dengan menggunakan SurveyMonkey. Agar data yang diperoleh lebih homogen maka target partisipan mencakup mahasiswa tanpa kriteria eksklusi. Tautan survei disosialisasikan melalui 
leaflets dan poster yang ditempelkan di lingkungan kampus Universitas X. Untuk meminimalkan social desirability, dalam informasi mengenai survei dinyatakan bahwa penelitian ini dimaksudkan untuk melihat dinamika pengalaman hidup sehari-hari. Untuk mencegah resistensi partisipan terhadap butir-butir pernyataan yang bersifat lebih sensitif, kuesioner yang mengukur orientasi terhadap kehidupan (Revised Life Orientation Test (LOT-R) (Scheier, Carver, \& Bridges, 1994) disajikan terlebih dahulu, diikuti kuesioner trait mindfulness (Mindfulness Attention Awareness Scale / MAAS) (Brown \& Ryan, 2003) dan diakhiri dengan kuesioner ketakutan terhadap kematian (Collett-Lester Fear of Death and Dying Scale / CL-FODS) (Lester, 1990; Lester \& Abdel-Khalek, 2003). Pada bagian penutup survei, partisipan diminta mengisi "security details" berupa huruf pertama kota kelahiran, huruf terakhir warna favorit, huruf pertama nama ibu kandung, jumlah saudara kandung, dan bulan kelahiran. Pengisian security details dimaksudkan mencegah kemungkinan partisipan mengisi survei lebih dari satu kali, misalnya karena ia ingin meningkatkan kesempatan dalam memenangkan prize draw. Undian untuk prize draw dilakukan dengan menggunakan https://www.random.org/ sehingga menghasilkan tiga pemenang dengan insentif masing-masing Rp 250.000.

Revised Life Orientation Test (LOT-R: Scheier, Carver, \& Bridges, 1994) merupakan modifikasi Life Orientation Test (Scheier \& Carver, 1985), dengan validitas prediktif dan diskriminan yang lebih adekuat. Partisipan memberikan nilai dalam skala Likert 5 -poin $(0=$ sangat tidak setuju dan $4=$ sangat setuju) terhadap 10 butir pernyataan tentang dirinya, namun hanya 6 butir saja yang mengukur ekspektansinya mengenai hal-hal baik dalam kehidupan (contoh, "Saya selalu optimis terhadap masa depan) sedangkan 4 butir lainnya berfungsi sebagai filler. Makin tinggi skor total LOT-R, makin optimis partisipan terhadap kehidupan. Kadar optimisme bersifat relatif stabil ketika diukur dalam jangka waktu beberapa minggu sampai 3 tahun (lihat Carver dkk., 2010). Reliabilitas LOT-R dalam penelitian ini adalah $\alpha=$ 0,551, serupa dengan penelitian Musabig dan Meinarno (2017) terhadap mahasiswa Program Diploma III Kebidanan di Indonesia.

Mindfulness Attention Awareness Scale (MAAS: Brown \& Ryan, 2003) terdiri dari 15 butir pernyataan untuk mengukur ketiadaan faktor tunggal atensi dan kesadaran tentang berbagai kondisi dalam kehidupan sehari-hari. Partisipan diminta untuk memberikan penilaian mengenai pengalamannya dalam skala Likert 6-poin (1 = hampir selalu dan $6=$ hampir tidak pernah; contoh, "Saya terpaku pada masa lalu dan masa depan". Makin tinggi skor total MAAS, makin tinggi trait mindfulness yang dilaporkan oleh partisipan. Validitas prediktif dari MAAS telah dilaporkan dalam banyak studi (Sauer dkk., 2013). Reliabiltas MAAS dalam studi terdahulu untuk sampel mahasiswa di Indonesia adalah $\alpha=0,770$ (Yusainy, 2013) dan untuk sampel komunitas adalah $\alpha=0,880$ (Yusainy \& Lawrence, 2014). Dalam penelitian ini diperoleh $\alpha=$ 0,810 .

Collett-Lester Fear of Death and Dying Scale (CL-FODS: Lester, 1990; Lester \& Abdel-Khalek, 2003) mengukur tingkat ketakutan seseorang ketika ia berpikir tentang kematian dan proses sekarat diri sendiri dan orang lain. Kuesioner ini telah divalidasi dalam berbagai konteks budaya dengan konsistensi internal yang baik (Groebe dkk., 2018). Kuesioner CL-FODS dalam penelitian ini menggunakan versi adaptasi berbahasa Indonesia dari Wicaksono (2003) dan Wicaksono \& Meiyanto (2003) yang secara total memuat 40 butir pernyataan. Partisipan memberikan nilai pada skala Likert 5-poin ( $1=$ "sangat tidak setuju" dan 5 = "sangat setuju") terhadap pernyataan mengenai seberapa terganggu dan cemasnya ia ketika memikirkan tentang kematian diri sendiri (10 butir; contoh, "Singkatnya kehidupan"), proses yang terkait dengan 
sekarat diri sendiri (10 butir; contoh, "Rasa sakit menjelang kematian"), kematian orang lain (10 butir; contoh, "Menua tanpa orang tersebut"), serta proses yang terkait dengan sekarat orang lain (10 butir; contoh, "Menyaksikan orang tersebut menderita kesakitan"). Tingkat ketakutan terhadap kematian yang semakin tinggi direfleksikan oleh skor CL-FODS yang lebih tinggi, baik skor total maupun skor setiap dimensi ketakutan. Dalam penelitian ini diperoleh $\alpha=$ 0,952 untuk seluruh butir CL-FODS, serupa dengan penelitian Wicaksono (2003) untuk sampel mahasiswa di Indonesia. Reliabilitas dimensi ketakutan terhadap kematian diri sendiri, proses sekarat diri sendiri, kematian orang lain, dan proses sekarat orang lain secara berturut-turut adalah $\alpha=0,908 ; 0,898$; 0,$838 ; 0,894$.

Untuk menguji hipotesis bahwa ketakutan terhadap kematian adalah fungsi dari (i) orientasi terhadap kehidupan (Hipotesis 1), (ii) trait mindfulness setelah memperhitungkan peran orientasi terhadap kehidupan (Hipotesis 2), dan (iii) moderasi trait mindfulness (Hipotesis 3), data hasil penelitian diuji dengan analisis regresi hirarki. Sebagai prediktor awal adalah orientasi terhadap kehidupan, dilanjutkan dengan trait mindfulness, dan diakhiri dengan interaksi antara orientasi terhadap kehidupan dan trait mindfulness. Pengujian analisis hirarki dilakukan sebanyak lima kali untuk memprediksi ketakutan terhadap kematian secara total dan dalam keempat dimensi ketakutan.

\section{HASIL DAN PEMBAHASAN}

Data SurveyMonkey mencatat bahwa dari total 280 mahasiswa Universitas $\mathrm{X}$ yang mengawali survei, 24 partisipan berhenti mengisi setelah kuesioner orientasi terhadap kehidupan, 25 partisipan berhenti setelah kuesioner trait mindfulness, dan 10 partisipan berhenti setelah kuesioner ketakutan terhadap kematian. Jumlah partisipan final yang mengisi seluruh kuesioner serta menyediakan data security details adalah 218 partisipan, terdiri atas 56 laki-laki $(26,415 \%)$ dan 156 perempuan $(73,585 \%)$. dengan rerata usia 20,840 tahun $(S D=1,777)$ dan rentang usia antara 17 sampai 27 tahun. Sebagian besar partisipan adalah mahasiswa Psikologi $(61,137 \%)$.

Statistik deskriptif dan asosiasi antar variabel orientasi terhadap kehidupan (LOT-R), trait mindfulness (MAAS), dan ketakutan terhadap kematian (CL-FODS) disajikan pada Tabel 1.

Tabel 1.

Statistik Deskriptif dan Asosiasi Orientasi Terhadap Kehidupan, Trait Mindfulness, dan Ketakutan Terhadap Kematian $(N=218)$

\begin{tabular}{llllllll}
\hline Kuesioner & $(1)$ & $(2)$ & $(3)$ & $(4)$ & $(5)$ & $(6)$ & $(7)$ \\
\hline LOT-R (1) & & & & & & & \\
MAAS (2) & $0,251^{* * *}$ & & & & & & \\
CL-FODS & $0,161^{*}$ & $-0,105$ & & & & & \\
$(3)$ & 0,125 & $-0,109$ & $0,834^{* * *}$ & & & & \\
KDS (4) & $0,148^{*}$ & $-0,108$ & $0,863^{* * *}$ & $0,706^{* * *}$ & & & \\
SDS (5) & $0,135^{*}$ & $-0,085$ & $0,835^{* * *}$ & $0,526^{* * *}$ & $0,595^{* * *}$ & & \\
KOL (6) & $0,135^{*}$ & $-0,045$ & $0,829^{* * *}$ & $0,497^{* * * *}$ & $0,585^{* * *}$ & $0,746^{* * * *}$ & \\
SOL (7) & 2,994 & 3,721 & 3,497 & 3,134 & 3,706 & 3,560 & 3,587 \\
\hline$M(S D)$ & $(0,487)$ & $(0,649)$ & $(0,653)$ & $(0,897)$ & $(0,768)$ & $(0,683)$ & $(0,759)$ \\
\hline
\end{tabular}

Keterangan:

LOT-R = Revised Life Orientation Test , MAAS = Mindfulness Attention Awareness Scale , CL-FODS = CollettLester Fear of Death and Dying scale; KDS = Dimensi kematian diri sendiri pada CL-FODS; SDS = Dimensi sekarat diri sendiri pada CL-FODS; KOL = Dimensi kematian orang lain pada CL-FODS; SOL = Dimensi sekarat orang lain pada CL-FODS.

$* p<0,05 ; * * * p<0,001$. 
Orientasi terhadap kehidupan berkorelasi positif dengan trait mindfulness $(p<0,001)$ dan ketakutan total terhadap kematian $(p=$ $0,017)$ serta sebagian besar dimensi ketakutan yaitu dimensi proses sekarat diri sendiri (SDS; $p=0,029$ ), kematian orang lain (KOL; $p=0,047)$, dan sekarat orang lain (SDS; $p=0,046$ ), namun tidak berkorelasi dengan dimensi ketakutan terhadap kematian diri sendiri (KDS; $p>0,065 ; n s$.). Trait mindfulness tidak berkorelasi dengan ketakutan total terhadap kematian dan keempat dimensi ketakutan ( $p s>0,110 ; n s$.). Interkorelasi ketakutan terhadap kematian secara total dan antar dimensi ketakutan tergolong tinggi ( $r s>0,829$; $p s<0,001)$.

Analisis awal berdasarkan data demografis partisipan menunjukkan bahwa usia tidak berkorelasi dengan orientasi terhadap kehidupan, trait mindfulness, dan ketakutan terhadap kematian ( $p s>0,086 ; n s$.). Respons yang diberikan mahasiswa Psikologi tidak berbeda dengan mahasiswa non-Psikologi ( $p s$ $>0,065 ; n s$.). Tidak ada perbedaan antar jenis kelamin dalam hal orientasi terhadap kehidupan $(p>0,387 ; n s$.$) dan trait$ mindfulness ( $p s>0,309 ; \quad n s$. ), namun dibandingkan partisipan laki-laki, partisipan perempuan melaporkan ketakutan yang lebih tinggi terhadap kematian secara total ( $t$ $(80,939)=0,473 ; p<0,001 ; M$ perempuan $=$ 3,$626 ; S D=0,584$ vs. $M$ laki-laki $=3,152$; $S D=0,740)$ dan dalam keempat dimensi ketakutan ( $p s<0,001$ ). Dengan demikian data demografis yang dimasukkan sebagai prediktor pada analisis regresi hirarki hanya variabel jenis kelamin partisipan.

Pengujian hipotesis penelitian melalui analisis regresi hirarki untuk variabel kriterium ketakutan total terhadap kematian (analisis ke-1) dan dimensi-dimensi ketakutan (analisis ke-2 sampai ke-5) disajikan pada Tabel 2. Untuk mengendalikan peran potensial jenis kelamin, variabel ini dimasukkan sebagai prediktor pada Step 1 dan dapat memprediksi varians ketakutan terhadap kematian (analisis ke-1:
$\left.\Delta R^{2}=0,100 ; p<0,001\right)$. Pada Step 2, skor orientasi terhadap kehidupan secara signifikan memberikan sumbangan varians yang terjelaskan sebesar 0,020 sehingga kekuatan prediksi $R^{2}$ meningkat menjadi $12,022 \%$. Orientasi terhadap kehidupan berperan memprediksi ketakutan yang lebih tinggi terhadap kematian (Hipotesis 1). Pada Step 3, skor trait mindfulness berkontribusi meningkatkan penjelasan varians sebesar 0,028 dan meningkatkan kekuatan prediksi $R^{2}$ menjadi 0,148. Dengan demikian, trait mindfulness memiliki validitas inkremental di atas orientasi terhadap kehidupan dalam memprediksi ketakutan yang lebih rendah terhadap kematian (Hipotesis 2). Pada Step 4, interaksi antara orientasi terhadap kehidupan dan trait mindfulness dimasukkan dalam analisis namun tidak memperkuat prediksi ketakutan terhadap kematian $\left(\Delta R^{2}<0,001 ; p\right.$ $=0,988 ; n s$.$) . Artinya trait mindfulness tidak$ berperan sebagai moderator korelasi antara orientasi terhadap kehidupan dan ketakutan terhadap kematian (Hipotesis 3). Koefisien $\beta$ untuk prediktor adalah jenis kelamin $(\beta=$ $0,472 ; t=4,900 ; p<0,001)$, orientasi terhadap kehidupan $(\beta=0,248 ; t=2,765 ; p$ $=0,006)$, trait mindfulness $(\beta=-0,174 ; t=-$ $2,582 ; p=0,011)$, dan interaksi antara orientasi terhadap kehidupan dan trait mindfulness $(\beta=0,002 ; t=0,015 ; p=0,988$; $n s$.). Secara keseluruhan, ketakutan yang lebih tinggi terhadap kematian diprediksi oleh kombinasi variabel jenis kelamin perempuan, orientasi yang bersifat optimis terhadap kehidupan, dan trait mindfulness yang rendah $\left(R=0,385 ; R^{2}=0,148 ; F(3\right.$, 208) $=12,044 ; p<0,001)$.

Ketika langkah-langkah analisis regresi hirarki diulang kembali untuk variabel kriterium dimensi-dimensi ketakutan terhadap kematian (lihat Tabel 2, analisis ke2 sampai ke-5), ditemukan bahwa kombinasi antara jenis kelamin perempuan, orientasi yang bersifat optimis terhadap kehidupan, dan trait mindfulness yang rendah secara konsisten memprediksi ketakutan yang lebih tinggi dalam dimensi kematian diri sendiri 
Tabel 2.

Analisis Regresi Hirarki Ketakutan terhadap Kematian dengan Prediktor Orientasi terhadap Kehidupan dan Trait Mindfulness $(N=218)$

\begin{tabular}{|c|c|c|c|c|c|c|c|}
\hline Analisis ke- & Kriterium & Step & Prediktor & $\Delta R^{2}$ & Total $R^{2}$ & Final beta & $p$ \\
\hline \multirow[t]{4}{*}{1} & CL-FODS & 1 & Jenis kelamin & $0,100 * * *$ & 0,100 & 0,437 & $<0,001$ \\
\hline & & 2 & LOT-R & $0,020 *$ & 0,120 & 0,191 & 0,030 \\
\hline & & 3 & MAAS & $0,028 * *$ & 0,148 & $-0,174$ & 0,010 \\
\hline & & 4 & LOT-R x MAAS & $<0,001$ & 0,148 & 0,002 & 0,988 \\
\hline \multirow[t]{4}{*}{2} & KDS & 1 & Jenis kelamin & $0,085^{* * *}$ & 0,085 & 0,596 & $<0,001$ \\
\hline & & 2 & LOT-R & 0,013 & 0,097 & 0,207 & 0,090 \\
\hline & & 3 & MAAS & $0,024 *$ & 0,121 & $-0,221$ & 0,018 \\
\hline & & 4 & LOT-R x MAAS & $<0,001$ & 0,121 & 0,002 & 0,988 \\
\hline \multirow[t]{4}{*}{3} & SDS & 1 & Jenis kelamin & $0,060 * * *$ & 0,060 & 0,432 & $<0,001$ \\
\hline & & 2 & LOT-R & $0,017 *$ & 0,077 & 0,207 & 0,050 \\
\hline & & 3 & MAAS & $0,026 *$ & 0,104 & $-0,199$ & 0,014 \\
\hline & & 4 & LOT-R x MAAS & $<0,001$ & 0,104 & 0,038 & 0,785 \\
\hline \multirow[t]{4}{*}{4} & KOL & 1 & Jenis kelamin & $0,086^{* * *}$ & 0,086 & 0,456 & $<0,001$ \\
\hline & & 2 & LOT-R & 0,013 & 0,098 & 0,157 & 0,089 \\
\hline & & 3 & MAAS & $0,021 *$ & 0,119 & $-0,157$ & 0,028 \\
\hline & & 4 & LOT-R x MAAS & 0,001 & 0,120 & $-0,066$ & 0,589 \\
\hline \multirow[t]{4}{*}{5} & SOL & 1 & Jenis kelamin & $0,055^{* *}$ & 0,055 & 0,596 & 0,001 \\
\hline & & 2 & LOT-R & 0,015 & 0,062 & 0,207 & 0,065 \\
\hline & & 3 & MAAS & 0,010 & 0,067 & $-0,221$ & 0,140 \\
\hline & & 4 & LOT-R x MAAS & $<0,001$ & 0,063 & $-0,002$ & 0,788 \\
\hline
\end{tabular}

Keterangan:

LOT-R = Revised Life Orientation Test; MAAS = Mindfulness Attention Awareness Scale; CL-FODS = CollettLester Fear of Death and Dying scale; KDS = Dimensi kematian diri sendiri pada CL-FODS; SDS = Dimensi sekarat diri sendiri pada CL-FODS; KOL = Dimensi kematian orang lain pada CL-FODS; SOL = Dimensi sekarat orang lain pada CL-FODS.

Mean-centering dilakukan pada seluruh variabel.

$* p<0,05 ; * * p<0,01$.

$\left(R=0,348 ; R^{2}=0,121 ; F(3,208)=9,561 ; p\right.$ $<0,001)$, proses sekarat diri sendiri $(R=$ 0,$322 ; R^{2}=0,104 ; F(3,208)=8,031 ; p<$ $0,001)$, dan kematian orang lain $(R=0,345$; $\left.R^{2}=0,119 ; F(3,208)=9,365 ; p<0,001\right)$. Khusus untuk dimensi ketakutan terhadap proses sekarat orang lain $\left(R=0,284 ; R^{2}=\right.$ $0,080 ; F(3,208)=6,060 ; p<0,001)$, trait mindfulness tidak memberikan kontribusi signifikan $(\beta=-0,119 ; t=-1,440 ; p=0,151$, $n s$.$) . Sejalan dengan hasil analisis ketakutan$ total terhadap kematian, asosiasi antara orientasi terhadap kehidupan dan keempat dimensi ketakutan juga tidak dimoderasi oleh trait mindfulness ( $p s>0,586 ; n s$.).

Kapasitas manusia untuk menyadari realita yang tengah ia jalani sekaligus membayangkan masa depan membawa konsekuensi kesadaran akan hadirnya kematian pada satu titik dalam kehidupannya. Berbeda dengan penelitian terdahulu (Brown, 2011; Sigal dkk., 2007), dalam penelitian ini individu dengan orientasi terhadap kehidupan yang lebih positif (semakin optimistis) melaporkan ketakutan yang lebih tinggi terhadap kematian. Sulit untuk memastikan apakah sifat optimistis yang berlebihan akan selalu membawa dampak negatif, namun dalam konteks dinamika ketakutan terhadap kematian, faktor optimisme memiliki arah korelasi yang positif. Pola ini ditunjukkan secara konsisten dalam hal ketakutan individu tersebut terhadap proses sekarat diri sendiri, kematian orang lain, dan proses sekarat orang lain.

Temuan utama penelitian ini adalah bahwa orientasi terhadap kehidupan secara konsisten memprediksi ketakutan total yang lebih tinggi terhadap kematian maupun 
dalam keempat dimensi ketakutan. Optimisme mengandaikan pada pikiran positif (positive thinking) akan masa depan. Kontra intuisi, dalam jangka waktu panjang, fantasi positif justru berperan dalam munculnya gejala depresi (Oettingen, Mayer, \& Portnow, 2016). Individu lanjut usia yang mengantisipasi masa depan yang lebih bahagia malah tidak bahagia satu tahun kemudian (Cheng, Fung, \& Chan, 2009). Eksperimen Yusainy (2017) menemukan bahwa keberadaan afek atau perasaan negatif dibutuhkan untuk mengaktivasi kapasitas partisipan dalam mengendalikan proses mental dan perilaku diri sendiri sesuai dengan standar yang ditetapkan (selfcontrol). Self-control merupakan prediktor bagi keberhasilan dalam banyak domain kehidupan (lihat tinjauan De Ridder, Lensvelt-Mulders, Finkenauer, Stok, \& Baumeister, 2012; Moffitt dkk., 2011), serta memiliki asosiasi negatif dengan ketakutan terhadap kematian (Gailliot, Baumeister, \& Schmeichel 2006). Dengan demikian, patut diduga bahwa dalam batas tertentu pesimisme dibutuhkan agar seseorang lebih siap menyusun langkah-langkah antisipasi dalam menghadapi kemungkinan gagal di masa depan.

Seiring dengan semakin banyaknya studi yang menemukan sisi negatif dari optimisme, seperti bias optimisme (Sharot, 2011), temuan penelitian ini berada dalam satu barisan yang sama. Manfaat baik dari optimisme perlu dikaji lebih mendalam mengingat secara umum masyarakat percaya bahwa konsep tersebut selalu membawa kepada kebaikan. Dalam konteks ketakutan terhadap kematian, dibutuhkan penelitian longitudinal mengenai optimisme bersamasama dengan konstruk lain yang membentuk kecenderungan memformulasikan "orientasi positif" (Caprara dkk., 2009; Oles \& Jankowski, 2018), seperti penilaian positif mengenai diri sendiri (self-esteem) dan kehidupan personal (kepuasan terhadap kehidupan).
Temuan kedua studi ini adalah bahwa orientasi terhadap kehidupan yang bersifat optimis perlu dikawal oleh trait mindfulness. Keberadaan trait mindfulness mampu memprediksi ketakutan yang lebih rendah terhadap kematian, di atas peran variabel orientasi terhadap kehidupan. Mindfulness pada prinsipnya melepaskan keterikatan terhadap penilaian positif maupun negatif (Hayes \& Feldman, 2004), dengan cara menjalani realita kehidupan apa adanya. Secara epistemik, mindfulness adalah metode yang berpusat pada pengenalan diri, pada bagaimana individu mengenali proses mental dan perilaku diri sendiri (Brown \& Ryan, 2003). Individu yang mindful terbiasa untuk mengamati dan menerima apapun pikiran, perasaan, dan perilaku diri sendiri sebagai sesuatu yang wajar, tanpa merasa perlu memberikan makna tertentu terhadap pengalaman tersebut. Pada penelitian ini tampak efek mindfulness bekerja dengan manifestasi spesifik berupa rendahnya dimensi ketakutan terhadap kematian dan proses sekarat diri sendiri.

Trait mindfulness partisipan dalam penelitian ini juga signifikan dalam memprediksi dimensi ketakutan yang lebih rendah terhadap kematian kematian orang lain. Mekanisme di balik temuan ini bisa jadi terkait dengan asosiasi positif antara mindfulness dengan kepedulian terhadap sesama (Brown, Ryan, \& Creswell, 2007). Di sisi lain, trait mindfulness tidak memprediksi dimensi ketakutan terhadap proses sekarat orang lain. Berbeda dengan kematian orang lain yang lebih sering disaksikan secara langsung dalam kehidupan sosial, misalnya pada saat menghadiri pemakaman, proses sekarat orang lain mungkin bukan merupakan hal yang kerap ditemui partisipan mahasiswa dalam penelitian ini. Artinya ada keberjarakan dengan peristiwa tersebut. Survei nasional Yun dkk. (2017) menemukan bahwa populasi umum, pasien penderita kanker, keluarga pasien, dan petugas kesehatan memiliki sikap yang berbeda terhadap beragam aspek kematian. Sebagai implikasinya, dinamika peran orientasi 
terhadap kehidupan dan trait mindfulness bisa jadi berbeda jika diujikan pada sampel komunitas yang beragam.

Lebih jauh, trait mindfulness tidak memiliki peran dalam memperkuat atau memperlemah hubungan antara orientasi terhadap kehidupan dan ketakutan terhadap kematian. Hal ini bisa dimaknai bahwa setidaknya dalam penelitian ini, mindfulness yang terbatas pada kecenderungan alamiah seseorang belum mampu menjadi moderator yang efektif. Penelitian eksperimental dengan menggunakan rancangan induksi state mindfulness dalam bentuk terstruktur perlu diujicobakan (Yusainy \& Lawrence, 2015). Konsep mindfulness berakar dari tradisi kontemplasi dan praktik meditasi yang memerlukan latihan sistematis, rutin, dan berdurasi panjang agar efeknya dapat meluas (lihat meta-analisis dan tinjauan sistematis Gu, Strauss, Bond, \& Cavanagh, 2015).

Pada seluruh analisis regresi hirarki yang diujikan, partisipan perempuan melaporkan ketakutan yang lebih tinggi terhadap kematian dibandingkan partisipan laki-laki, terlepas dari orientasi terhadap kehidupan dan trait mindfulness mereka. Kecenderungan ini telah ditemukan pada riset-riset klasik di bidang thanatology (Dattel \& Neimeyer, 1990). Perbedaan proses mental dan perilaku antar jenis kelamin dapat diasosiasikan dengan pebedaan fokus pada aktivitas neural, karena perempuan lebih terfokus pada pengalaman internal dan lakilaki lebih terfokus pada stimulus eksternal (Moriguchi, Touroutoglou, Dautoff, Dickerson, \& Barrett, 2014). Ketakutan terhadap kematian dimaknai sebagai pengalaman internal yang menyiratkan fungsi evolusioner perempuan sebagai penjaga kehidupan berimplikasi pada hal ini.

\section{SIMPULAN}

Penelitian ini dimaksudkan untuk memetakan dinamika peran orientasi terhadap kehidupan dan trait mindfulness dalam memprediksi ketakutan terhadap kematian. Analisis pendahuluan menunjukkan bahwa individu dengan orientasi terhadap kehidupan yang lebih positif (semakin optimistis) melaporkan ketakutan terhadap kematian yang lebih tinggi, baik secara total maupun dalam sebagian besar dimensi spesifik ketakutan. Dalam model regresi hirarki dengan prediktor jenis kelamin, orientasi terhadap kehidupan, dan trait mindfulness, ditemukan bahwa optimisme memprediksi ketakutan yang lebih tinggi terhadap kematian secara total dan dalam seluruh dimensi spesifik ketakutan. Trait mindfulness memiliki validitas inkremental di atas orientasi terhadap kehidupan dalam memprediksi ketakutan terhadap kematian, namun trait ini tidak berperan sebagai moderator korelasi antara orientasi terhadap kehidupan dan ketakutan terhadap kematian. Secara keseluruhan, kombinasi antara optimisme yang lebih tinggi, trait mindfulness yang rendah, dan jenis kelamin perempuan memprediksi ketakutan yang lebih tinggi terhadap kematian. Penelitian selanjutnya perlu dilakukan dalam setting eksperimen, misalnya melalui induksi kesadaran seseorang mengenai kematian (mortality salience), untuk memetakan hubungan kausal antara orientasi terhadap kehidupan, mindfulness sebagai trait dan state, serta berbagai cara proksimal dan distal dalam menghadapi ketakutan terhadap kematian. Terlepas dari keterbatasan yang ada, hasil penelitian ini dapat dimanfaatkan sebagai salah satu masukan bagi strategi mengelola ketakutan terhadap kematian dengan memperhitungkan peran perbedaan individual.

\section{UCAPAN TERIMA KASIH}

Terima kasih kepada Fakultas Ilmu Sosial dan Ilmu Politik Universitas Brawijaya atas dana hibah untuk penelitian ini.

\section{DAFTAR PUSTAKA}

Arndt, J., Routledge, C., Cox, C. R., \& Goldenberg, J. L. (2005). The worm at the core: A terror management perspective on the roots of 
psychological dysfunction. Applied and Preventive Psychology, 11, 191-213. doi: 10.1016/j.appsy.2005.07.002

Brown, A. G. (2011). An examination of the relationship between death anxiety, optimism, depression, and anxiety. Dissertation. Lubbock: Texas Tech University.

Brown, K. W., \& Ryan, R. M. (2003). The benefits of being present: Mindfulness and its role in psychological well-being. Journal of Personality and Social Psychology, 84(4), 822-848. doi: 10.1037/0022-3514.84.4.822.

Brown, K. W., Ryan, R. M., \& Creswell, J. D. (2007). Mindfulness: Theoretical foundations and evidence for its salutary effects. Psychological Inquiry, 18(4), 211-237. doi:10.1080/10478400701598298.

Becker, E. (1973). The denial of death. New York: Simon \& Schuster.

Caprara, G. V., Fagnani, C., Alessandri, G., Steca, P., Gigantesco, A., Sforza, L. L. C., \& Stazi, M. A. (2009). Human optimal functioning: the genetics of positive orientation towards self, life and the future. Behavior Genetics, 39, 277-284. doi: 10.1007/s10519-0099267-y.

Carver, S. C., Scheier, M. F., \& Segerstrom, S. C. (2010). Optimism. Clinical Psychology Review, 30, 879-889. doi: 10.1016/j.cpr.2010.01.006

Cheng, S. T., Fung, H. H., \& Chan, A. C. (2009). Self-perception and psychological well-being: The benefits of foreseeing a worse future. Psychology and Aging, 24, 623-633. doi: $10.1037 / \mathrm{a} 0016410$.

Dattel, A. D., \& Neimeyer, R. A. (1990). Sex differences in death anxiety: Testing the emotional expressiveness hypothesis. Death Studies, 14(1), 1-11, doi: 10.1080/07481189008252341.

De Ridder, D. T., Lensvelt-Mulders, G., Finkenauer, C., Stok, F. M., \& Baumeister, R. F. (2012). A metaanalysis of how trait self-control relates to a wide range of behaviors. Personality and Social Psychology Review, 16(1), 76-99. doi: $10.1177 / 1088868311418749$.

Gailliot, M. T., Schmeichel, B. J., \& Baumeister, R. F. (2006). Selfregulatory processes defend against the threat of death: Effects of self-control depletion and trait self-control on thoughts and fears of dying. Journal of Personality and Social Psychology, 91(1), 49 - 62. doi: 10.1037/00223514.91.1.49.

Gu, J., Strauss, C., Bond, R. \& Cavanagh, K. (2015). How do mindfulness-based cognitive therapy and mindfulnessbased stress reduction improve mental health and wellbeing? A systematic review and meta-analysis of mediation studies. Clinical Psychology Review, 37 , 1-12. doi: 10.1016/j.cpr.2015.01.006.

Greenberg, J., Pyszczynski, T., \& Solomon, S. (1986). The causes and consequences of a need for self-esteem: A terror management theory. Dalam R. F. Baumeister (Ed.), Public self and private self (pp. 189-212). New York: Springer.

Groebe, B., Strupp, J., Eisenmann, Y., Schmidt, H., Schlomann, A., Rietz, C., \& Voltz, R. (2018). Measuring attitudes towards the dying process: A systematic review of tools. Palliative Medicine, 32(4), 815-837. doi: $10.1177 / 0269216317748889$. 
Hayes, A. M., \& Feldman, G. (2004). Clarifying the construct of mindfulness in the context of emotion regulation and the process of change in therapy. Clinical Psychology: Science and Practice, 11(3), 255-262.

Hecht, D. (2013). The neural basis of optimism and pessimism. Experimental Neurobiology, 22, 173-199. doi: 10.5607/en.2013.22.3.173

Hirschberger, G., Pyszczynski, T., Ein-Dor, T., Shani Sherman, T., Kadah, E., Kesebir, P., \& Park, Y.V. (2016). Fear of death amplifies retributive justice motivations and encourages political violence. Peace and Conflict: Journal of Peace Psychology, 22(1), 67-74. doi: 10.1037/pac0000129

Iverach, L., Menzies, R. B., \& Menzies, R. E. (2014). Death anxiety and its role in psychopathology: Reviewing the status of a transdiagnostic construct. Clinical Psychology Review, 34(7), 580-593. doi: 10.1016/j.cpr.2014.09.002

Lester, D. (1990). The Collett-Lester Fear of Death Scale: The original version and a revision. Death Studies, 14, 451-468. doi: 10.1080/07481189008252385

Lester, D., \& Abdel-Khalek, (2003). The Collett-Lester Fear of Death Scale: A correction. Death Studies, 27, 81-85. doi: 10.1080/07481180302873

Lyke, J. (2013). Associations among aspects of meaning in life and death anxiety in young adults. Death Studies, 37(5), 471-482.

doi:

$10.1080 / 07481187.2011 .649939$

Musabig, S. A., \& Meinarno, E. A. (2017). Optimisme sebagai prediktor psikologis pada mahasiswa kebidanan. Jurnal Psikologi dan Kesehatan Fakultas Kedokteran dan Kesehatan Universitas
Muhammadiyah Jakarta, 13(2), 134143. doi: 10.24853/jkk.13.2.134-143

Moffitt, T., Arseneault, L., Belsky, D., Dickson, N., Hancox, R., Harrington, H. L., .. Caspi, A. (2011). A gradient of childhood self-control predicts health, wealth, and public safety. Proceedings of the National Academy of Sciences, 108(7), 2693-2698. doi: 10.1073/pnas.1010076108

Moriguchi, Y., Touroutoglou, A., Dautoff, R., Dickerson, B.C., Barrett, L. F. (2014). Sex differences in the neural correlates of affective experience. Social Cognitive and Affective Neuroscience, 9(5), 591-600. doi: 10.1093/scan/nst030

Niemiec, C. P., Brown, K. W., Kashdan, T. B., Cozzolino, P. J., Breen, W. E., Levesque-Bristol, C., \& Ryan, R. M. (2010). Being present in the face of existential threat: The role of trait mindfulness in reducing defensive responses to mortality salience. Journal of Personality and Social Psychology, 99, 344-365. doi: 10.1037/a0019388

Oettingen, G., Mayer, D., \& Portnow, S. (2016). Pleasure now, pain later: Positive fantasies about the future predict symptoms of depression. Psychological Science, 27(3), 345-353. doi: 10.1177/0956797615620783

Oleś, P., \& Jankowski, T. (2018). Positive orientation - $\mathrm{a}$ common base for hedonistic and eudemonistic happiness? Applied Research in Quality of Life, 13(1), 105-117. doi: 10.1007/s11482017-9508-9

Pyszczynski, T., Solomon, S., \& Greenberg, J. (2015). Thirty years of Terror Management Theory. Advances in Experimental Social Psychology, 52. 170. doi: 10.1016/bs.aesp.2015.03.001. 
Sauer, S., Walach, H., Schmidt, S., Hinterberger, T., Lynch, S., Büssing, A., Kohls, N. (2013). Assessment of mindfulness: Review on state of the art. Mindfulness, 4(1), 3-17. doi: 10.1007/s12671-012-0122-5.

Scheier, M. F., \& Carver, C. S. (1985). Optimism, coping, and health: Assessment and implications of generalized outcome expectancies. Health Psychology, 4, 219-247. doi: 10.1037/0278-6133.4.3.219

Scheier, M. F., Carver, C. S., \& Bridges, M. W. (1994). Distinguishing optimism from neuroticism (and trait anxiety, self-mastery, and self-esteem): A reevaluation of the Life Orientation Test. Journal of Personality and Social Psychology, 67, 1063-1078. doi: 10.1037//0022-3514.67.6.1063

Sharot, T. (2011). The optimism bias. Current Biology, 21(23), R941-R945. doi: 10.1016/j.cub.2011.10.030

Sigal, J. J., Ouimet, M. C., Margolese, R., Panarello, L., Stibernik, V., \& Bescec, S. (2007). How patients with lessadvanced and more-advanced cancer deal with three death-related fears: An exploratory study. Journal of Psychosocial Oncology, 26, 53-68. doi: 10.1300/J077v26n01_04

Silarus, A. (2015). Sadar penuh, hadir utuh. Jakarta: TransMedia Pustaka.

Solomon, S., Greenberg, J., \& Pyszczynski, T. (1991). A terror management theory of social behavior: The psychological functions of self-esteem and cultural worldviews. Advances in Experimental Social Psychology, 24, 93-159. doi: 10.1016/S0065-2601(08)60328-7

Solomon, S., Greenberg, J., \& Pyszczynski, T. (2015). The worm at the core: The role of death in life. New York: Random House.

Steger, M. F., Kashdan, T. B., Sullivan, B. A., \& Lorentz, D. (2008). Understanding the search for meaning in life: Personality, cognitive style, and the dynamic between seeking and experiencing meaning. Journal of Personality, 76(2), 199-228.

Weinstein, N., Brown, K. W., \& Ryan, R. M. (2009). A multi-method examination of the effects of mindfulness on stress attribution, coping and emotional wellbeing. Journal of Research in Personality, 43, 374-385. doi: 10.1111/j.1467-6494.2007.00484.x

Wicaksono, W. (2003). Ketakutan terhadap kematian ditinjau dari kebijaksanaan dan orientasi religiusitas pada periode remaja akhir yang berstatus mahasiswa. Tesis. Yogyakarta: Program Pascasarjana Fakultas Psikologi Universitas Gadjah Mada.

Wicaksono, W., \& Meiyanto, S. (2003). Ketakutan terhadap kematian ditinjau dari kebijaksanaan dan orientasi religiusitas pada periode remaja akhir yang berstatus mahasiswa. Jurnal Psikologi, 2, 57-58. doi: 10.22146/jpsi.7032

Yun, Y. H., Kim, K-N., Sim, J-A., Lee, J., Choo, J., An, A.,... Hae Jung, K. (2017). Attitudes of the general population, cancer patients, their family caregivers, and physicians toward dying and death: A nationwide survey. Global Journal of Health Science, 9, 201-11. doi: 10.5539/gjhs.v9n10p201

Yusainy, C. (2013). Overcoming aggression: Musing on mindfulness and selfcontrol. Dissertation. Nottingham: School of Psychology University of Nottingham. 
Yusainy, C. (2017). Feeling full or empty inside? Peran perbedaan individual dalam struktur pengalaman afektif. Jurnal Psikologi, 44(1), 1-17. doi: 10.22146/jpsi.18377

Yusainy, C., \& Lawrence, C. (2014). Relating mindfulness and aggression to harm to the self and to others. Personality and Individual Differences,
64(1), $\quad$ 78-83. doi: 10.1016/j.paid.2014.02.015

Yusainy, C., \& Lawrence, C. (2015). Brief mindfulness induction could reduce aggression after depletion. Consciousness and Cognition, 33(1), 125-134. doi: 